\title{
Psychiatry in the age of neuroscience: the impact on clinical practice and lives of patients
}

\author{
Elleke Landeweer • Tineke Abma • \\ Jolijn Santegoeds · Guy Widdershoven
}

Published online: 12 December 2008

(C) The Author(s) 2008. This article is published with open access at Springerlink.com

\begin{abstract}
Due to the progress being made in the neurosciences, higher expectations for the use of medication, even against the patient's will, are arising in mental hospitals. In this article, we will discuss whether the neurosciences and new psychopharmacological solutions really support patients who suffer from mental illnesses. To answer this question, we will focus on the perspective of patients and their experiences with psychiatric (coercive) treatments. The analysis of one person's story shows that other issues besides appropriate medication are important for recovery from a mental illness. In daily life, issues such as coping, rehabilitation and social support are of major importance for a patient suffering from psychiatric disease. Thus, although progress in the neurosciences is a positive development for clinical practice, it does not mean that (coercive) medication alone will carry a patient into recovery. A patient's recovery is dependent, not only upon the process of finding the appropriate medication and trust between the psychiatrist and the patient, but also upon relational aspects, such as being recognised as a person, belonging, accepting responsibilities, developing friendships and trusting others. These findings lead to the conclusion that dealing with psychiatric diseases is more complex than what the biomedical model of neuroscience suggests and that one should include the social context of the patient in the recovery process.
\end{abstract}

J. Santegoeds is a consultant for clinical psychiatric practice, human right activist and founder of the foundation Mindrights; http://www.mindrights.nl. This article is inspired by her personal experiences in psychiatry.

E. Landeweer $(\bowtie) \cdot$ T. Abma $\cdot$ G. Widdershoven

Department of Health, Ethics and Society/Metamedica, Faculty of Health, Medicine and Life

Sciences, School for Public Health and Primary Care (Caphri), Maastricht University,

PO Box 616, 6200 MD Maastricht, The Netherlands

e-mail: e.landeweer@zw.unimaas.nl; e.landeweer@hes.unimaas.nl

J. Santegoeds

Mindrights, Eindhoven, The Netherlands 
Zusammenfassung Aufgrund des Fortschritts der Neurowissenschaften steigen die Erwartungen an die Anwendung von Arzneimitteln in psychiatrischen Kliniken - auch gegen den Willen der Patienten. Im vorliegenden Artikel gehen wir der Frage nach, ob die Neurowissenschaften und innovative Psychopharmaka Patienten mit psychischen Erkrankungen tatsächlich helfen. Dabei konzentrieren wir uns auf die Sicht der Patienten und deren Erfahrungen mit (zwangsverabreichten) Psychopharmaka. Bei der Analyse einer Patientengeschichte wird deutlich, dass auch noch andere Aspekte als die medikamentöse Behandlung bei der Heilung psychischer Erkrankungen eine Rolle spielen. Im täglichen Leben sind bei der Auseinandersetzung mit einer psychischen Erkrankung Themen wie das Zurechtkommen, Rehabilitation und soziale Unterstützung für die Patienten von großer Bedeutung. Das bedeutet zwar, dass der Fortschritt der Neurowissenschaften für die klinische Praxis als positiv zu bewerten ist, nicht aber, dass allein (zwangsverabreichte) Medikamente zur Genesung des Patienten führen. Allein die richtige Medikation zu finden erfordert ein Vertrauensverhältnis zwischen Psychiater und Patient. Es geht aber auch um soziale Aspekte wie das Gefühl der Anerkennung als Person, Zugehörigkeit, Eigenverantwortung, Freundschaften und Vertrauen gegenüber anderen Menschen. Diese Erkenntnisse lassen die Schlussfolgerung zu, dass der Umgang mit psychischen Erkrankungen sehr viel komplexer ist als das von den biomedizinischen Modellen der Neurowissenschaften suggeriert wird, und dass eine Einbeziehung des sozialen Kontexts der Patienten für den Heilungsprozess unerlässlich ist.

Résumé Suite aux progrès des neurosciences, on observe une demande accrue de médication par les hôpitaux psychiatriques, parfois même à l'encontre de la volonté des patients. Dans cet article, nous nous interrogeons sur la pertinence des neurosciences et des nouvelles approches psychopharmacologiques dans le traitement des patients atteints de maladies mentales. À cette fin, nous examinons le point de vue du patient dans son expérience avec les traitements psychiatriques (coercitifs). L'analyse d'une histoire personnelle montre qu'il existe divers facteurs essentiels, autres que la médication, qui entrent en cause dans la guérison d'une maladie mentale. Au quotidien, des aspects tels que l'accompagnement, la réhabilitation et le support social se révèlent d'une importance majeure pour les patients atteints de troubles psychiatriques. Ainsi, même si les progrès en neurosciences s'avèrent positifs pour la pratique clinique, cela ne veut pas dire que la médication (coercitive), seule, mènera le patient à la guérison. En effet, cette guérison ne dépend pas uniquement de la découverte du médicament approprié et de la relation de confiance qui s'établit entre le psychiatre et son patient. Elle est aussi tributaire de la dimension relationnelle de la vie du patient, telle la reconnaissance individuelle, le sentiment d'appartenance, la prise de responsabilité, le développement d'amitiés et la confiance en autrui. Ces révélations nous mènent à la conclusion que la gestion des désordres psychiatriques est beaucoup plus complexe que le modèle des neurosciences le suggère et que le processus de traitement du patient inclus impérativement son contexte social. 


\section{Introduction}

During the last two decades of the twentieth century, both psychiatrists and their patients have steadily recognised that mental illnesses are diseases of the brain that can be understood and treated using established scientific tools.

(Andreasen 2001)

Recent developments in the neurosciences are promising. Neuroscience gives us, not only insight into how the brain works, but also claims to produce new scientific solutions to repair the brain, as the above quote illustrates. Psychopharmaca, it is said, can eventually repair any mental disorder. Because of the claimed progress in neuroscientific research, clinical psychiatry now aims to apply the methods and results from this line of research to the assessment of diagnoses and the treatment of psychiatric diseases. Among psychiatrists and patients in mental hospitals, higher expectations are arising from the use of medication. For instance, in a context where, as a consequence of a mental disorder, a patient becomes a danger to others, most psychiatrists consider medication the best way to avert the danger (as opposed to seclusion or the use of other physical restraints, such as bandages). This is the case even if medication is supplied against the patient's will (Landeweer et al. 2007).

In this paper we want to discuss whether the neurosciences and the new psychochemical solutions really support patients who are dealing with a psychiatric disorder. Is the progress in the neurosciences a welcome development for patients who suffer from mental illnesses? To answer this question, we will focus on the perspective of the patients and their experiences with psychiatric treatments. We will discuss the story of Jolijn, a consultant and co-author of this article, who spent her adolescence in a mental hospital. Jolijn's story demonstrates two important issues that are relevant for recovering from, or coping with, a psychiatric disease. The first issue is finding the appropriate medication. This is not a simple and unambiguous process of administering drugs; rather, it requires deliberation and dialogue between the patient, the psychiatrist, and those people in the social surrounding of the patient. The second issue is that, even when the appropriate medication is found, this alone is not always sufficient for the process of recovery. The social context of the patient is important as well and cannot be ignored.

Jolijn's story, as well as other empirical data used in this paper, was gathered from stakeholders in clinical psychiatry (patients, family, psychiatrists and nurses) as part of an empirical-ethical evaluation of the Dutch Act on Coercive Measures in Mental Hospitals (Landeweer et al. 2007). This study was completed over a period of 14 months, from February 2006 to March 2007, and conducted by three partners (Free University of Amsterdam, Maastricht University and the Prismant Research Institute). The Dutch Ministry of Health financed the study. A commission made up of experts from the field gave their recommendation to the Ministry on the basis of six studies. Our study focused on the use of restraints inside mental hospitals and consisted of 37 open interviews (12 former patients; 10 family members, 15 caregivers), three focus groups (two former patients; one family member) and an expert meeting with psychiatrists, legal experts and representatives from patient and family member organisations in the Netherlands. The findings from this study were 
published along with other evaluation studies of the Dutch Psychiatric Compulsory Admissions Act in May 2007.

The aim of this paper is to show that in daily life, issues like coping, rehabilitation and social support are of major importance for the patient suffering from a psychiatric disease. First, we will start by explaining the biomedical model of mental illness which prevails in the neurosciences, and the impact it has on clinical practice. Then we will present the story of Jolijn and her experiences dealing with a psychiatric disorder, followed by her recovery. Finally, we will discuss what this story teaches us about recovery from psychiatric diseases. We will offer a suggestion about how to include the social context of the patient, in addition to the approach of the neurosciences, into the recovery process. One of the leading themes is that psychiatry has two legacies: the natural sciences (neurosciences) as well as the humanities. Both legacies should be integrated into the conceptualisation and treatment of psychiatric disorders.

\section{The impact of the neurosciences on clinical practice}

The neurosciences study the neural structures and dynamics that make perception, thought, memory, emotion and behaviour possible (Bennett and Hacker 2003). In our empirical-ethical study of the Dutch Psychiatric Compulsory Admissions Act, we noticed that, influenced by developments in the neurosciences, clinical psychiatry uses a biomedical model to explain deviant behaviour in terms of neurological dysfunctions. The biomedical model is functional within the neurosciences and, with its focus on the physiological aspects of the brain, it has produced new scientific insights into the chemical causes of psychiatric disorders. Yet, the biomedical model also has consequences for diagnosis and treatment in clinical psychiatry. Psychiatric diseases are regarded as temporal disturbances of normal neuro-functioning in the brain which, following this model, can and should be repaired through the use of appropriate medication. The patient is seen as a biological actor who is (temporally) restrained by chemical processes in the brain.

Under the influence of the neurosciences, clinical psychiatry is tempted to classify itself as part of an independent faculty within the medical sciences. In the interviews we conducted in mental hospitals, most of the psychiatrists regarded their profession as medical. Like physical diseases, which can be seen as harmful physical dysfunctions which can be cured by medication, psychiatric diseases can also be regarded as a dysfunction of the physical system which can be treated using advanced psychopharmaca. The primary responsibility of the psychiatrist is to assess the right diagnosis and to determine what kind of medication is necessary for recovery. Mental disorders are understood as biomedical disorders that can be cured (as opposed to chronic conditions that entail a capricious process of recovery and rehabilitation).

The biomedical model of psychiatric diseases has an impact on the clinical practice of psychiatrists, nurses and patients. Psychiatrists consider themselves more and more as physicians who can fix a psychiatric disorder like a doctor repairing a broken leg. In one of the interviews, a psychiatrist compared himself with a surgeon, 
who gives treatments to patients in emergency situations without patient's consent. The quote below illustrates this.

“As a medical practitioner I'm not any different from a surgeon. They don't have to wait for consent in case they arrive at an accident by helicopter. They immediately start giving the treatment that is necessary to save lives".

The idea is that psychiatry, as a profession, should focus on repairing the dysfunctions of the brain. In clinical practice, this means finding the right medication for disorders (Double 2002). Although this focus is important, the question remains whether, and to what extent, this strategy is experienced as beneficial by patients having to cope and deal with chronic mental disorders. Is medication alone sufficient to handle one's illness and its accompanying uncertainties and feelings, and to find a new perspective in life? Is recovering from a psychiatric disease only a matter of taking the appropriate medication and restoring the chemical imbalances in the brain to normal functioning? We will argue that, in daily life, having a psychiatric disease and coping with it is a much more complex process. Even repairing a broken leg does not automatically mean that the patient can immediately walk again: The patient has to undergo physiotherapy to strengthen the muscles, has to cope with uncertainties ("Will I be able to walk again?") as well as physical and other limitations (such as difficulties in mobility). The patient also needs encouragement from those in his or her social surrounding to fully recover. Likewise, one can question whether in psychiatry, taking the appropriate medication is enough to restore a patient's normal functions.

The biomedical model creates an identity problem in theory as well as in practice. In theory there is the discussion of the mind-body problem in the context of neuroscience and psychiatry. For example, Bennett and Hacker, in their work, Philosophical Foundations of Neuroscience (2003), draw attention to the conceptual confusion which exists in the neurosciences. They point to a mereological fallacy in the reductionist framework for neuroscience: the primary focus on the brain as the part where psychological attributes (of the mind) are located is meaningless because the proper subject matter can only be the whole human being. The mind and its psychological attributes have to be considered as a process and not as an object-like entity. In clinical practice, psychiatrists experience a dualistic position. On the one hand, they use a naturalistic perspective in diagnosing and subscribing medication ('erklären') and want to develop a more naturalistic identity, like somatic physicians. On the other hand, they have to interpret and give meaning to the stories of the patients who are suffering from psychiatric diseases ('verstehen'). But this second characteristic of clinical practice seems less scientifically valid (Nieweg 2005).

We claim that both perspectives are necessary in order to provide good clinical care during a patient's recovery process. Which perspective should lead depends on the person and his or her circumstances and features. As we feel that nowadays the humanistic approach to psychiatry has become undervalued, in the next paragraph we will give voice to a former patient by presenting the story of Jolijn, a woman who suffered a major depression in her adolescence. In this story it will become clear that patients do not experience recovery as a linear (physical) process, as the 
biomedical model supposes. In spite of the developments in the neurosciences, recovery from a mental illness is still not always possible. Most of the time recovery is about accepting limitations that spring from the illness, as well as discovering what the patient (still) can do. Deegan (1988) describes the process of recovery as an urge, a wrestle and a resurrection. Patients have to find ways to cope with a mental disorder, and develop new values in accepting a different life perspective. This perspective on recovery differs from the perspective of the biomedical model. To improve clinical practice, psychiatrists must listen to the stories of patients in order to develop a mutually acceptable treatment strategy. Accepting and overcoming a mental illness is a broader paradigm than repairing dysfunctions by administering the appropriate medication.

\section{The impact of neuroscience on the lives of patients: a patient's story}

In the context of our empirical-ethical research on coercive measures in mental hospitals, we spoke with Jolijn about her experiences with coercion. In an open, conversational interview, we asked her about her experiences and opinions of coercive treatments in psychiatry. During the interview she told us her life story. She related how she was involuntary admitted to a mental hospital and how she eventually got out again. The interview lasted 1.5 hours, was tape-recorded, completely transcribed, and analysed using a narrative framework (Lieblich et al. 1998). Later on in the process, the respondent was again consulted to give feedback on our presentation of her story in this paper. Jolijn approved of our description, and her responses have been included in this version.

Jolijn was 16 years old when she felt her life was not worth living anymore. She felt lonely and miserable because of all the changes that had happened in her life. Her parents had broken up, her mother had had a nervous breakdown, and she could not get along with her father. At that stage in her life she decided to take an overdose of medication to commit suicide. After a hospital stay during which she tried to cut her wrists, she was, without her consent, admitted to a mental hospital.

Her experiences with the first mental hospital where she stayed were not good. She did not trust the staff and the staff did not trust her. She kept on trying to commit suicide, which brought her long periods in the seclusion room against her will. She was convinced that the staff of the mental hospital could and would not help her. She refused medication, but was forced to use it. The coercive measures made her think there was no way out of her misery. The medication made her drowsy and she experienced only negative effects. She distrusted her body, felt poisoned and even compared this to being raped. The relationship between Jolijn and the staff of the hospital worsened. Trust between them was on such a low level that, when she accidentally cut her Achilles tendon right in front of the eyes of the staff, they did not believe the symptoms of this irregular injury and it took weeks before she could get the medical treatment she needed. Eventually this led to her being transferred to another hospital. By that time she had just reached 18 years of age. In this second hospital, Jolijn's experiences with the staff were much better. Jolijn described her impressions on how they treated her: 
Then I got transferred to another hospital. The staff said to me, 'You have been traumatised by the staff of the previous ward. We want to make you feel safe again'. And that division was actually really nice. There was some sort of match between the staff and me. You could really laugh with them. We went to the movies or just for a drink. I felt recognised as a person, like I was allowed to participate in normal life, where before I was not.

Although her experiences at this hospital were much better, after a while she decided she wanted to get out. As the staff did not think she was ready to leave, she ran away and started living on the streets. It took her some time to find a place of her own to live, but when she found it, she picked up normal life, went back to school and got her degree. Later on she became politically active in the patient rights movement. At this moment, Jolijn is successfully leading an action group against seclusion rooms and is pleading for better treatment of (young) people in mental hospitals. She is regularly invited to international congresses to tell her story and help to improve psychiatric practice.

When we look at her recovery, it gives us a good perspective on the aspects that, according to Jolijn, are important for recovery from a major depression such as hers. In the following section we will look more closely at her experiences of being given medication against her will and how that eventually led to her using marihuana; she considers this an effective form of self-medication. After that, we will discuss the fact that, although this self-medication was part of her recovery, it alone was not enough to help her find meaning in life. Support and recognition from her friends and family, along with being allowed to participate in society were, according to her, important aspects in her being able to recover.

\section{Experiences with medication}

In the story of Jolijn, self-medication proved important for her recovery. But during her stay at the first mental hospital, lack of trust prevented her from finding the appropriate and right dose of medication. The medication she received against her will, she said, did not help her at all. It made her feel frightened and insecure. She no longer trusted her own thoughts and she felt poisoned. It made her distress even worse. Since she was already receiving strong medication, starting to smoke marihuana proved to be a small step when some other patients offered this to her. She described her first experience of smoking marihuana as follows:

Before my admission, I actually was very athletic. I didn't smoke and swam in competitions all the time. So I wasn't interested in using drugs or anything. But as I was already receiving so many chemicals, it wasn't so difficult anymore to start with smoking marihuana. Well, aren't illegal drugs just medicines that can't be bought in a drugstore?

Jolijn describes her first experience of using marihuana as a moment of change. For the first time in a long time she felt a sense of happiness. She recalls in a lively way this unforgettable moment in her recovery trajectory: 
When I first used marihuana, it was the first time in two years that I felt some happiness inside. I just sat against the wall, feeling so amazed I could feel this well. I just forgot about all the shit. It remains drugs of course, but it really had an impact on me. For me, this was the moment that changed everything. Feeling good seemed possible all of a sudden.

Starting to use marihuana "changed everything", according to Jolijn. It gave her control again, and made her aware of her capabilities and forgotten possibilities in life. She experienced positive feelings, which before seemed impossible. Problems with her parents at home, concerns over her physical well-being and struggles with the staff, all moved to the background, and new perspectives emerged. The start of her recovery story was triggered by the chemical influences of her neurological state. The marihuana helped her to feel more self-confident and in control. However, we cannot say that her recovery solely depended on her use of (self-administered) medication. Her use of marihuana started after she got in contact with other patients in the hospital. They offered her marihuana, and implicitly stimulated her to actively take responsibility for the direction of her own life. Her fellow patients did not force her to take the marihuana like the doctors forced her to take the medication, but rather invited her to either choose or refuse the drugs. Jolijn experienced that she had a choice (accepting or refusing the drugs), and rediscovered her own agency and responsibility—responsibility not only for herself, but also for others, since her fellow patients trusted her in keeping the secret of smoking in the hospital. Still another aspect that eventually fostered the process of Jolijn's recovery was the psychiatrist who approved that using marihuana was a better option than cutting herself. Jolijn experienced his approval as another important stimulus which urged her to continue her new, unconventional but creative and effective way of dealing with her illness, as the following quote shows:

I started smoking marihuana, and then I didn't cut myself anymore. I was not depressed all the time anymore. The psychiatrist acknowledged that using marihuana was a better option than cutting myself.

The story of Jolijn illustrates that the use of this self-administered medication contributed to her recovery, but that recovery is not about (self-administered) medication alone. For Jolijn, the fact that the use of marihuana was her own choice made her feel in control. The decision offered to her by her fellow patients triggered a process of empowerment. Jolijn became a subject (versus an object), and a moral agent who took responsibility for her life again.

Jolijn's story also demonstrates that recovery through medication is a dynamic process of intensive social interactions with others, including fellow patients and professional experts. Finding the appropriate medication for an individual is a process of searching and experimenting (versus the standard linear application of scientific knowledge in terms of 'this diagnosis requires that medication') requiring a close co-operation between psychiatrist and patient. There should be a basis of trust between patients and psychiatrists so that patients will not feel out of control. Trust is an important condition to discuss and deliberate upon in terms of symptoms and side effects. Attention should be given to the fears and prejudices that exist 
(Widdershoven and Abma 2007). From the story of Jolijn, we conclude that recovery is not only about finding the right medication for a particular psychiatric disease, it is also about finding the right medication for the particular person who is suffering from a certain psychiatric disease. The medication should match the personal values and individual circumstances of the patient. For Jolijn, the use of marihuana was a starting point. It gave her hope and it addressed her ability to fight instead of addressing her self-destructive behaviour. The story shows that chemical substances can be important for recovery, but only as one step in the process and in a context where the person feels safe and can trust the medication and the person administering it.

With this preliminary conclusion, we can assert that the work of a psychiatrist should not only be about administering medication. It should also be about creating trust, consensus, motivation and empowerment. Through this approach, patients become partners and co-owners of their treatment of medication, will accept and trust medication more, will find better solutions to fit their situation and, hence, may experience the beneficial aspects of pharmacotherapy. In the next paragraph, we will discuss which other steps are important in the recovery process.

\section{Coping and rehabilitation}

If we look at the social context in the story of Jolijn, we find that for her, recovery meant finding meaning in her life again. The medication she received against her will did not make her feel better. Instead, it was her self-administered medication that gave her strength and confidence. The social support from others to cope with life was of major importance as well. Jolijn experienced a caring, supportive attitude in the second hospital where the staff made her responsible for her own life. For example, instead of the punishment she was expecting, because she acted against the rules by going out for a day, she received a compliment when she returned. The staff did not rigidly stick to the hospital rules, but rather was able to view the situation from a positive angle. Jolijn was able to take on her own responsibilities. The positive feedback fostered a trusting working relationship between Jolijn and the staff (as opposed to the tense struggle with the staff in the first hospital). Jolijn remembers how surprised she was

After I spent a day outside the hospital against regulations, I was prepared for a major punishment. But then they said, 'You have come back without any problems, so you have proven that you are able to handle more freedom'. So instead of a punishment, I got a compliment! That was really nice.

For Jolijn, rehabilitation meant being treated as a person and a moral agent with capabilities to direct her own life, and not primarily as a patient. Getting her own responsibilities meant that the staff trusted her. This recognition made her trust the staff in return, despite her previous experiences in the first hospital. It became possible for her to identify with them. This basic recognition of being a person and a moral agent served as the beginning of Jolijn's opening up to other persons and developing new perspectives. The staff asked Jolijn what she wanted in her life. 
They made her reconsider such questions which motivated her not to become what they called a 'chrono', a person who will never be leaving the hospital.

They gave me a lot of respect and pointed out my own responsibilities and wishes in life. They said: 'If you could choose a kind of hobby or sport, what would you choose?' Well, I hadn't thought about what I wanted for two yearsI was only thinking about how I could kill myself. At first I was dazed; I didn't know what to want. But it brought humanity back to me.

So according to Jolijn, her recovery was also about belonging to a group of peers, enjoying and participating in life and being recognised as a person. Taking over responsibilities (again), making contact, developing friendships and trusting others were important aspects of her recovery. Recovery is more than explaining and repairing psychiatric diseases. For persons suffering from a psychiatric disorder, it is also important to cope with the illness and to find new meaning in life with a chronic disorder.

In the following paragraph we will further reflect on the implications of Jolijn's story for the biomedical model of the neurosciences, and for clinical practice.

\section{Recognition and trust}

The biomedical model certainly has benefits for persons with psychiatric diseases. It explains what is happening when a person experiences a mental illness by referring to dysfunctions of the brain and suggests that the solution is to take the appropriate medication and repair the malfunctions. But this explanatory story does not fully relate to the actual stories of patients such as Jolijn. As she pointed out in her story, some significant aspects are neglected if clinical psychiatry only addresses this model. Clinical psychiatry aims to heal the patient and focuses on the patient's wellbeing. What exactly is in the best interests of the patient is not objectively given, but rather determined and constructed by (inter)personal factors. First, one of the consequences is that finding the proper medication is a difficult process and cannot be simplified. Every person has different physical features and this complicates finding the right match of medication. Standard solutions are furthermore problematic because of the severe side effects they sometimes cause (Helmchen 2005). As the story of Jolijn shows, it is also important that patients trust the medication. Dialogue and deliberation are necessary in order to arrive at a constructive pathway to recovery. Coercive medication is less effective because of the stress and distrust it causes. Second, for Jolijn, being recognised as a person and a moral agent with her own responsibilities, along with developing friendships and trusting others, appeared just as important as finding the right medication. Those were the conditions which had to be met in order to make her recovery possible.

The way the biomedical model looks at persons with psychiatric diseases does not fully do justice to the patients' experiences in daily life. Patients hardly explain their disabilities in neuroscientific medical terms. Jolijn mainly refers to aspects in the social context. Other patients also experience their disabilities not as primarily biological, but mainly as social (Deegan 1988). Clinical psychiatry's 
focus on well-being and recovery demands a broader model to include these relevant factors. People need to find hope (that bad times will pass), empowerment (to trust in their own power to change and to direct their lives), acceptance of their own responsibilities in the recovery process and the development of a social role in society.

In mental hospitals, most professionals consider (coercive) medical treatment as the best option in order to avert dangerous behaviour. Yet it is important to realise that clinical psychiatry is more complex than that. Trust and recognition seem to be important features for clinical practice aiming at and working on the recovery of psychiatric disorders (in terms of coping with the illness, instead of repairing it). From the perspective of patients, medication alone is not enough to help them in their recovery. As the story of Jolijn shows, coercive medication can even worsen things. This means that, even in the context of a crisis, professionals should try to balance medical treatment with the narratives involved. They should strive for dialogue and deliberation with the patient to come to a joint perspective of what is in the best interest of the patient. This implies a shift from a paternalistic to a deliberative relationship in which patients become partners and co-owners of their own treatment. Active engagement of patients in their recovery process means that patients are recognised as persons with unique capabilities and possibilities for growth.

Honneth (1995) defends the importance of recognition for the well-being of persons in The Struggle for Recognition (1995). Recognition is seen as a vital human need. Inspired by Hegel, Honneth defends the claim that full human flourishing depends on the existence of well-established 'ethical' relations of mutual recognition. He identifies intersubjective conditions based on the establishment of relationships of mutual recognition for individual growth and development, which makes sense considering Jolijn's story. Based on modern social theory, he divides personal development into three modes: the development of self-confidence, selfrespect and self-esteem, which can only be acquired and maintained intersubjectively. These modes are developed by mutual recognition as a person in relationships of love and friendship (self-confidence), through recognition as an autonomous person (self-respect) and as a particular, unique person (self-esteem). In the story of Jolijn, we see that the vital human need of mutual recognition was of major importance for her recovery. Being recognised as a person (as opposed to being treated solely as a patient), at first by fellow patients and later by the staff in the second hospital, helped her to regain confidence about her own strength. Because Jolijn was being treated nicely in the second hospital (and even could have a laugh with the staff), she felt invited and allowed to participate in normal life again. This paved the way for her to create new perspectives on life, and to see how she could live a meaningful life even with a psychiatric disorder. Jolijn became less selfdestructive and developed hope for the future. She identified with the staff and they mutually trusted each other more and more.

Mutual recognition cannot develop without a foundation of mutual trust. Annette Baier (1994) acknowledges that trust is a basic condition for every good that can exist and develop within mutual relationships. Trusting each other is a complex and vulnerable process, but also an inevitable one. In all sorts of ways, we depend on 
each other, and for that, we have to trust each other. Especially in the clinical setting of psychiatry, patients are in a vulnerable position. They depend on the physicians in order to recover from a mental illness and to leave the hospital. Trust means giving some discretionary power and control over one's self to another person, thus becoming vulnerable. If a person is betrayed or disappointed, it is difficult to rebuild a trusting relationship. In the first hospital, the staff and Jolijn distrusted each other. The professional-patient relationship was characterised by strife, conflict, struggle and ignorance instead of mutual engagement, co-operation and agreement. The staff distrusted Jolijn to such an extent that eventually, they did not believe her when she said she had injured her Achilles tendon. Likewise, Jolijn distrusted the staff. They had admitted her to the hospital against her will. She did not have any reason to trust them. They did not convince her they were looking after her best interests. In the second hospital, a trusting relationship did develop. Jolijn came to trust the staff of that hospital because the staff acknowledged (recognised) her as a person and as a moral actor (and not primarily as a patient). They also trusted her to handle her own responsibilities.

Although mutual recognition and trust are difficult processes, the story of Jolijn shows that these are vital ingredients for recovery. Patients should become partners and co-workers of their own recovery. Some critical psychiatrists might object to this, by referring to the fact that developing a trusting relationship with mutual recognition is not always possible, according to the type of psychiatric disorder at hand, for instance in the case of a psychosis. Sometimes distrust can be part of the psychopathology. We do not seek to deny that building trust is a difficult process. The clinical practice of psychiatry can be frustrating and complex, and most of the time it is very hard to reach any success. However, despite the fact that clinical practice is confronted with frustrations and difficulties, we still claim that trust and recognition are vital ingredients to eventually creating a perspective on recovery for persons with psychiatric disorders. The primary focus should always be on restoring and building trust. Mutual trust and recognition eventually create the necessary context for repairing any dysfunctionings of the brain. Within that context, psychopharmaca can be of assistance in the recovery process.

\section{Conclusion}

In this paper we have made a case for a patient's perspective on recovery as an important extension and correction of the biomedical model of the neurosciences. We have illustrated this with Jolijn's story, which offers the perspective of a former patient who was involuntarily admitted to a mental hospital. This story shows us that involuntary medication did not have a beneficial effect on the patient's wellbeing and recovery. Finding medication that the patient can trust is a deliberative process wherein recognition as a person, personal growth and taking responsibilities are important, instead of being seen primarily as a patient. We concluded that medication alone is not enough for recovery. Medication should match with the wishes and values of the person suffering from the mental illness. Another aspect that the story of Jolijn made clear was that, for her recovery, other things were just 
as important as using medication. Being recognised as a person, belonging within a social setting, taking on her own responsibilities, developing friendships and trusting others determined her recovery. These findings lead to the conclusion that dealing with psychiatric diseases is more complex than the biomedical model presupposes and that one should include the social context of the patient into the recovery process. Mutual trust and recognition are vital ingredients for the success of clinical psychiatric practice. To create a mutual and overall recovery story, professionals must strive for dialogue and deliberation with the patient and aim to arrive at a joint perspective of what is necessary in psychiatry, as a practice of healing persons.

In order to develop a beneficial recovery model in clinical psychiatry, professionals should acknowledge that their role and identity are more complex than a naturalistic perspective in diagnosing and subscribing medication ('erklären') supposes. The perspective of the patients shows us that understanding and relating to the stories of patients ('verstehen') cannot be ignored if one wants recovery and coping to succeed. As Jolijn put it.

It is not that the healthcare workers don't want to develop good care, but traditions are difficult to change. Psychiatry deals with specific problems. People need education and guidance to eventually get on with their lives. That's what the main goal of psychiatry should be.

Open Access This article is distributed under the terms of the Creative Commons Attribution Noncommercial License which permits any noncommercial use, distribution, and reproduction in any medium, provided the original author(s) and source are credited.

\section{References}

Andreasen NC (2001) Brave new brain. Conquering mental illnesses in the era of the genome. Oxford University Press, New York

Baier AC (1994) Moral prejudices. Essays on ethics. Harvard University Press, Cambridge/MA

Bennett MR, Hacker PMS (2003) Philosophical foundations of neuroscience. Blackwell Publishing, Oxford

Deegan PE (1988) Recovery: the lived experience of rehabilitation. Psychosoc Rehabil J 11(4):11-19

Double D (2002) The limits of psychiatry. Br Med J 324(7342):900-904

Helmchen H (2005) Forthcoming ethical issues in biological psychiatry. World J Biol Psychiatry 6(Suppl 2):56-64

Honneth A (1995) The struggle for recognition. The moral grammar of social conflicts. Polity Press, Cambridge

Landeweer E, Abma T, Berghmans R, Janssen W, Dute J, Widdershoven G. (2007) Dwangtoepassing binnen de instelling. Ministerie van Volksgezondheid, Welzijn en Sport, Den Haag

Lieblich A, Tuval-Mashiach R, Zilber T (1998) Narrative analysis. Reading, analysis and interpretation. Thousand Oaks, Sage

Nieweg EH (2005) De psychiater in spagaat—over de kloof tussen natuur-en geesteswetenschappelijke psychiatrie. Tijdschrift voor psychiatrie 47(4):239-248

Widdershoven G, Abma T (2007) Hermeneutic ethics between practice and theory. In: Ashcroft RE, Dawson A, Draper H, McMilan JR (eds) Principles of health care ethics, 2nd edn. Wiley, London, pp 215-221 